\title{
PROSES PEWARNAAN ANYAMAN MANSIANG DI JORONG TARATAK KUBANG KABUPATEN LIMA PULUH KOTA
}

\author{
Yolanda Pratama Isfi ${ }^{1 *}$, Sri Zulfia Novrita ${ }^{2 *}$ \\ Pendidikan Kesejahteraan Keluarga Jurusan Ilmu Kesejahteraan Keluarga Fakultas Pariwisata dan Perhotelan \\ Universitas Negeri Padang \\ Jl. Prof. Dr. Hamka, Air Tawar Padang, Kel. Air Tawar Barat, Kec. Padang Utara, Kota Padang, Kode Pos 25132 \\ Sumatera Barat. Indonesia \\ Email: yolandaisfi35@gmail.com,srizulfianovrita@gmail.com
}

\begin{abstract}
Abstrak
Penelitian ini tentang proses pewarnaan anyaman mansiang Jorong Taratak Kubang Kabupaten Lima Puluh Kota yang menggunakan pewarna sintetis basis pada proses pewarnaan anyaman daun tumbuhan wlingi atau mansiang. Zat warna sintetis basis mudah diperoleh di pasaran, warna terjamin, memiliki warna yang beragam dalam proses penggunaanya yang praktis, dan lebih mudah dilakukan dalam proses pewarnaannya. Tujuan dari penelitian ini untuk mendeskripsikan resep dan proses pewarnaa mansiang di Rumah Anyaman Tabuan Jaya, Jorong Taratak Kubang Kabupaten Lima Puluh Kota. Metode yang digunakan dalam penelitian ini adalah metode deskriptif kualitatif, jenis data berbentuk data primer dan sekunder, informan penelitian ini ialah ketua kelompok dan anggota kelompok di Rumah Anyaman Tabuan Jaya, Jorong Taratak Kubang Kabupaten Lima Puluh Kota. Instrumen penelitian ini, berpedoman pada hasil observasi, wawancara, dokumentasi, serta data foto dan video. Untuk mendapatkan keabsahan data penulis memperoleh dari hasil pengamatan serta triangulasi. Analisis data didapatkan melalui reduksi data, penyampaian data dan penarikan kesimpulan.Hasil penelitian ini yaitu resep yang digunakan di Rumah Anyaman Tabuan Jaya untuk pencelupan memakai volt 1:10,dengan zat warna 0,05 gr x jumlah air (l). Untuk bahan proses pewarnaan anyaman dengan menggunakan zat warna basis pada Rumah Anyaman Tabuan Jaya dengan cara dicelup, proses pencelupan atau pewarnaan dengan menggunaakan panci, air yang dipanaskan masukan zat pewarna basis tunggu hingga air mendidih lalu dicelup selama kurang lebih 5-10 menit warna-warna yang dihasilkan berupa, merah, pink, kuning, jingga, biru, hijau, hitam,biru kehiataman, abu-abu, dan sebagaiya.
\end{abstract}

Kata Kunci: pewarnaan, anyaman, mansiang, wlingi.

\begin{abstract}
This research is about the coloring of mansiang weaving in Jorong Taratak Kubang, District of Lima Puluh Kota which uses synthetic dyes based on the process of coloring the woven leaves of the wlingi or mansiang plant. Synthetic base dyes are easy to find in the market, guaranteed colors, have a variety of colors in the process of using them which are practical, and easier to do in the coloring process. The purpose of this study is to describe the recipe and process of coloring mansiang at the Tabuan Jaya Woven House, Jorong Taratak Kubang, Lima Puluh Kota District. This research method is a qualitative descriptive method, the type of data is primary and secondary data, the informants of this research are the group leader and group members at the Tabuan Jaya Woven House, Jorong Taratak Kubang, Lima Puluh Kota District. The instrument of this study is the researcher herself, accompanied by observation guidelines, interview guidelines, documentation guidelines, and recording equipment (cameras). The validity of the data was obtained through persistence of observation and triangulation. Data were analyzed by data reduction, data presentation and drawing the conclusion.The results of this study are the recipes used at the Tabuan Jaya Woven House. It can be concluded that the immersion volt is 1:10 and pigment 0.05gr $x$ lots of water (l)process using the base dye at the Tabuan Jaya Weaving House by dyeing, the dyeing or coloring process is to use a pan filled with heated water, then add the base dye, wait until the water boils. Then the fabric is dyed for about 5-10 minutes. The colors produced are, red, pink, yellow, orange, blue, green, black, blueblac, gray.
\end{abstract}

Keywords: coloring, weaving, mansiang, wlingi.

\section{PENDAHULUAN}

Sumatera Barat memiliki beragam keunikan budaya daerahnya masing-masing. Seperti karya seninya, banyak karya seni yang ada di Sumatera Barat diantaranya, seni sastra, musik, tari, dan kerajinan yang beragam, salah satunya kerajinan tekstil. Kerajinan 
tekstil yang ada di Sumatera Barat berupa kain, tenunan, bordir, sulaman dan anyaman. Banyak jenis anyaman yang ada di Sumatera Barat seperti, anyaman pandan, anyaman bambu, anyaman rotan dan anyaman mansiang yang terdapat di daerah Kabupaten Lima Puluh Kota, yang bertempatan di Jorong Taratak Kubang kecamatan Guguak.

Menurut Minarsih \& Zubaedah (2012: 185) Anyaman merupakan kegiatan menyilangkan bahan dasar dari tumbuh tumbuhan yang dijadikan suatu gugusan yang kokoh serta dapat digunakan. Banyak jenis anyaman yang ada di Sumatera Barat seperti, anyaman pandan yang ada di daerah Ulakan Kabupaten Padang Pariaman, di daerah Muaro Pingai, Kabupaten Solok, anyaman bambu yang ada di daerah Palupuah Agam, dan di daerah Koto Baru Simalanggang, anyaman rotan yang ada di Lubuk Begalung dan anyaman mansiang yang terdapat didaerah Taratak salah satu Jorong di Kubang, Kecamatan Guguak di Kabupaten Lima Puluh Kota.

Daerah Jorong Taratak Kubang, merupakan salah satu sentra penghasil anyaman mansiang, di Sumatera Barat, Anyaman ini terbuat dari tumbuhan wlingi (Actinoscirpus grossuss) yaitu sejenis rumput yang termasuk kedalam takson teki tekian (cyperaceae) yang biasanya tumbuh di paya, rawa-rawa atau tempat tempat yang digenangi air, seperti kolam dan sawah, tanaman ini termasuk tanaman gulma yang banyak ditemui di Jorong Taratak Kubang, sehingga dimanfaatkan masyarakat Jorong Taratak Kubang untuk dijadikan kerajinan.

Dahulunya anyaman mansiang hanya dapat menghasilkan kerajinan dengan warna alami, namun seiring berjalanya waktu anyaman mansiang makin berkembang baik dari bentuk dan warnanya sehingga bisa menghasilkan berbagai macam kerajinan yang lebih bervasiasi dengan berbagai warna. Lebih jauh, warna-warna yang digunakan di Rumah Anyaman Tabuan Jaya banyak menggunakan warna-warna cerah, seprti merah, pink, jingga, ungu, dan hijau, dan terdapat juga warna-warna gelap berupa hijau lumut, blueblack dan hitam, namun dalam percampuran warna pada pewarnaan anyaman mansiang, tersebut tidak adanya takaran dalam pewarnaanya, sehingga tidak dapat menghailkan warna yang sama. Oleh sebab itu maka penulis tertarik meneliti tentang Proses dan Takaran Pewarnaan Anyaman Mansiang Jorong Taratak Kubang Kabupaten Lima Puluh Kota Studi Kasus di Rumah Anyaman Tabuan Jaya.

\section{KAJIAN TEORI}

\section{Anyaman}

Anyaman merupakan teknik dalam dalam menghsilkan seni kirya yang bisa dibuat dengan cara menumpang tindihkan (menyilangkan). Bahan-bahan anyaman dapat diperoleh dari tumbuh-tumbuhan yang sudah dikeringkan sebelumnya, serupa akar, daun, lidi, rotan untuk dijadikan suatu gugusan yang kokoh. Alat yang digunakan pada proses menganyam sangat sederhana, mudah ditemui, seperti pisau dan penipis (Patria \& Mutmaniah, 2015).

Menurut Bahrudinetal (2020) Anyaman dibagi menjadi tiga klarifikasi, yaitu anyaman datar, anyaman miring, dan anyaman persegi, anyaman datar biasanya dibuat dengancara memebntuk datar, lebar dan pipih,biasanya digunakan untuk membuat tikar,anyaman miring,biasanya dibuat untuk membuat keranjang dan sebaginya, anyaman persegi merupakan anyaman yang memiliki motif berbentuk geometris seperti segi tiga, empat, lima delapan dan sebagainya.

Berdasarkan pendapat diatas dapat disimpulkan bahwa Anyaman merupaka cara untuk menghasilkan sebuah karya seni rupa yang dapat dilakukan dengan cara menumpang tindihkan bahan anyam, baik menggunakan Teknik anyaman datar, anyaman miring atau anyaman persegi. Bahan-bahan anyaman, seperti akar, lidi, rotan, dan dedaunan untuk dijadikan suatu gugusan yang kokoh. Alat untuk menganyam sangat sederhana dan mudah didapatkan seperti pisau pemotong, pisau dan penipis.

\section{Pencelupan}

(Noor, 2007) mendeskripsikan"pencelupan merupakan proses memasukan warna pada tekstil secara merata menggunakan bahan yang sama pada seluruh bagian bahan tekstil, (Setiati, 2008:12) "Pencelupan dikerjakan dengan cara memasukan pewarna ke dalam air mendidih dan memasukkan serat yang mau diwarnai, kemudian merebus serat selama kurang lebih 10 menit".

Berdasarkan pendapat diatas dapat disimpulkan bahwa pencelupan merupakan proses pemasukan atau pemberian zat warna pada seluruh bagian bahan yang dalam proses mencelup ada beberapa faktor yang mempengaruhi seperti, perbandingan zat, suhu lama proses pencelupan dan pengaruh sifat bahan yang dicelup. 
Gorga : Jurnal Seni Rupa

Volume 10 Nomor 02 Juli-Desember 2021

p-ISSN: 2301-5942 | e-ISSN: 2580-2380

\section{Zat Warna}

(Suarsa, Suarya, \& Kurniawati, 2011) Zat pewarna sintetis mempunyai keleihan dibandingkan dengan zat pewarna alami seperti, mudah didapatkan, warna tetap, beragam macam warna, dan lebih mudah dan efisen dalam penggunaanya. Selai itu pewarna sintetis, bersifat tetaap,stabil, lebih tahan terhadap berbagai kondisi lingkungan, daya mewarnainya lebih kuat dan memiliki rentang warna yang lebih luas.

(Herlina \& Palupi, 2013) Zat warna kimia (sintetis) merupakan zat warna yang mudah diperoleh, memiliki kompoisi yang tetap, memiliki beanekaragam warna, praktis dalam penggunaanya yang memiliki afinitas kimia terhadapbenda yang diwarnai, jenis zat warna kimia zat warna diek, zat warna asam, basa, napthol, belerang,pigment, disperse, reakti, indigosol, dst.

Dari pendapat diatas dapat disimpulkan bahwa zat warna sinetis atau kimia mempunyai kelebihan memiiki afintitas yang baik, dan warna warna yang beraneka ragam,penggunaanya yang mudah dan praktis, dan memiliki komposisi yang tetap.

\section{METODE PENELITIAN}

Metode penelitian ini berupa metode deskriptif kualitatif, jenis data berupa data primer dan sekunder, informan penelitian ini ialah ketua kelompok dan anggota kelompok di Rumah Anyaman Tabuan Jaya, Jorong Taratak Kubang Kabupaten Lima Puluh Kota. Peneliti merupakan Instrumen dari penelitian ini, berpedoman pada hasil observasi, wawancara, dokumentasi, serta data foto dan video. Untuk mendapatkan keabsahan data penulis memperoleh dari hasil pengamatan serta triangulasi. Analisis data didapatkan melalui reduksi data, penyajian data serta penarikan kesimpulan.

\section{HASIL DAN PEMBAHASAN}

\section{Hasil}

Berdasarkan penelitian ini ditemukan bahwa resep yang digunakan untuk pencelupan yaitu dengan volt 1:10 dan untuk zat warna 0,05 gr/l x jumah air dalam bentuk liter, proses pewarnaan anyaman dengan cara di celup.

\section{Pembahasan}

\section{1). Resep Pewarnaan Anyaman Mansiang}

Bahan atau resep yang digunakan dalam proses pewarnaan daun tumbuhan wlingi atau mansiang yaitu zat warna basis, zat warna basis ini diperoleh dengan cara membeli, menurut (Setiati, 2008:12) Zat warna basis terdiri dari kombinasi atau perpaduan amino basis, jadi larutan zat warna bersifat basis. Basis memiliki warna cemerlang serta dapat langsung mewarnai bahan yang berasal dari serat hewani seperti sutera dan wol. Ningsih T (2015: 73) menjelaskan bahwa:

"Zat warna basis juga disebut sebagai pewarna nophal, sedangkan pada industri batik pewarna sejenis adalah pewarna napthol. Perbedaan antara pewarna basis dan pewarna napthol yaitu ketika proses pewarnaan. Zat warna napthol memakai air dingin untuk proses mewarnai, sedangkan pewarna basis memakai metode perebusan dengan air yang mendidih dalam proses pewarnaan. Warna-warna yang dihasilkan pewarna basis, diantaranya: warna merah, kuning hijau dan, biru. jika igin mendapatkan warna berbeda, maka dapat mencampurkan zat wana sesuai dengan yang di harapkan".

Dan (Agustina et al., 2011) menjeaskan bahwa, Pewarna yang pakai dalam pencelupan ini yaitu pewarna sintetis basis yang juga dikenal dengan pewarna kationik, karena mengandung ion positif (kationik). Zat warna basis sering juga disebut dengan pewarna universal karena sifatnya yang sulit dihilangkan dan bersifat permanen. Zat pewarna basis tergolong kedalam kategori tahan luntur pencucian tinggi, tetapi ketahanan yang kurang terhadap intensitas cahaya. Keunggulan penggunaan zat pewarna basis pada tekstil yaitu mempunyai variasi warna yang beragam jugs rentangan warna yang luas, cemerlang, tetap, permanen, dan kuat terhadap situasi dan kondisi keadaan alam, memiliki intensitas warna yang kuat. mudah didapat, ekonomis dan sederhanan dalam penggunaanya.

Jadi zat warna basis merupakan zat warna yang serupa degan zat warna napthol, perbedaanya yaitu saat mewarnai napthol menggunakan air dingin saat proses pewarnaan sedangkan basisi atau nophal menggunakan perebusan dengan air yang mendidih pada proses pewarnaanya, zat warna basis memiliki warna yang dapat memberi warna pada bahan yang berasal dari serat binatang secara langsung seperti sutera dan wol, Warna-warna dari zat warna basis tersebut terdiri dari warna merah, kuning hijau dan, biru. Apabila menginginkan warna yang lebih bervariatif, bisa mencampurkan zat pewarna tersebut sesuai dengan warna yang diharapkan. Resep yang digunakan di Rumah Anyaman Tabuan Jaya dengan resep pewarnaan untuk pencelupan volt $1: 10$, dan disetiap 200 gr mansiang atau daun tumbuhan wlingi menggunakan 0,1 gr zat warna dengan air $2000 \mathrm{ml}$. Jadi dapat disimpulkan: 


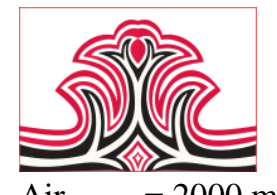

Air $\quad=2000 \mathrm{ml}$

Berat bahan (satu ikat mansiang) $=200 \mathrm{gr}$

Zat warna $=0,1 \mathrm{gr}$

$$
\begin{array}{rllc}
\text { Volt }= & \text { Berat bahan } & : & \text { Air } \\
= & 200 \mathrm{gr} & : & 2000 \\
= & 1 & : & 10
\end{array}
$$

Zat Warna $=0,05 \mathrm{gr} / \mathrm{l} \times$ jumlah air $(\mathrm{l})$

$$
\begin{aligned}
& =0,05 \mathrm{gr} / \mathrm{l} \times 2 \mathrm{l} \\
& =0,01 \mathrm{gr}
\end{aligned}
$$

Dengan zat warna $0,1 \mathrm{gr}$.

\section{2). Proses Pewarnaan Anyaman Mansiang}

Teknik atau proses pewarnaan di Rumah Anyaman Tabuan Jaya yaitu dengan pencelupan. Noor (2008:17) mendeskripsikan bahwa "pencelupan merupakan pemberian warna pada tekstil secara merata menggunakan bahan yang sama pada seluruh bagian bahan tekstil". Jadi suhu, dalam kesetimbangan, penyerapan pewarna suhu tinggi kurang dari penyerapan suhu rendah, tetapi dalam praktik kesetimbangan sulit dicapai, sehingga umumnya pencelupan memerlukan pemanasan untuk bereaksi untuk mempercepat, pengaruh perbandingan larutan juga mempengaruhi hasil warna, pengaruh bahan pewarnaan (Arifin 2009:3).

(Setiati, 2008:12) "Pencelupan dikerjakan dengan cara memasukan pewarna ke dalam air mendidih dan memasukkan serat yang mau diwarnai, kemudian merebus serat selama kurang lebih 10 menit".

Berdasarkan pendapat diatas dapat disimpulkan bahwa pencelupan merupakan proses pemasukan atau pemberian zat warna basis pada seluruh bagian daun wlingi atau mansiang yang dalam proses mencelup ada beberapa faktor yang mempengaruhi seperti, perbandingan zat, suhu lama proses pencelupan dan pengaruh sifat bahan yang dicelup.

Berdasarkan teori diatas sesuai dengan proses pewrnaan yang ada di Rumah Anyaman Tabuan Jaya menggunakan volt 1:10 untuk pencelupan dan 0,1 gr untuk setiap 200 gr mansiang. Berat yang dibutuh kan saat pencelupan yaitu air $2000 \mathrm{ml}$ atau 2l, mansiang atau daun wlingi $200 \mathrm{gr}$, dan zat warna 0,1 gr, pencelupan dilakukan dengan cara, panaskan air hingga hangat lalu masukan zat warna 0,1 gr tunggu hingga mendidih lalu masukan daun wlingi atau mansiang kedalam larutan, dengan waktu kurang lebih 5-10 menit sambail dibolak balik, semakin lama proses pencelupan, maka warna yang dihasilkan akan semakin pekat. pencelupan dilakukan secara merata hal ini dapat dilihat dari, hasil setelah daun wlingi atau mansiang selesai diwarnai dan kering.
Gorga : Jurnal Seni Rupa

Volume 10 Nomor 02 Juli-Desember 2021 p-ISSN: 2301-5942 | e-ISSN: 2580-2380

Hasil Pewarnaan daun wlingi atau mansiang dengan bahan pewarna sintetis dengan zat warna basis yaitu hijau, pink, merah, ungu, jingga, dan juga ada hasil warna dari percampuran warna-warna diatas sehingga menjadi warna, hitam, hijau lumut, abu-abu, biru kehitaman dst.

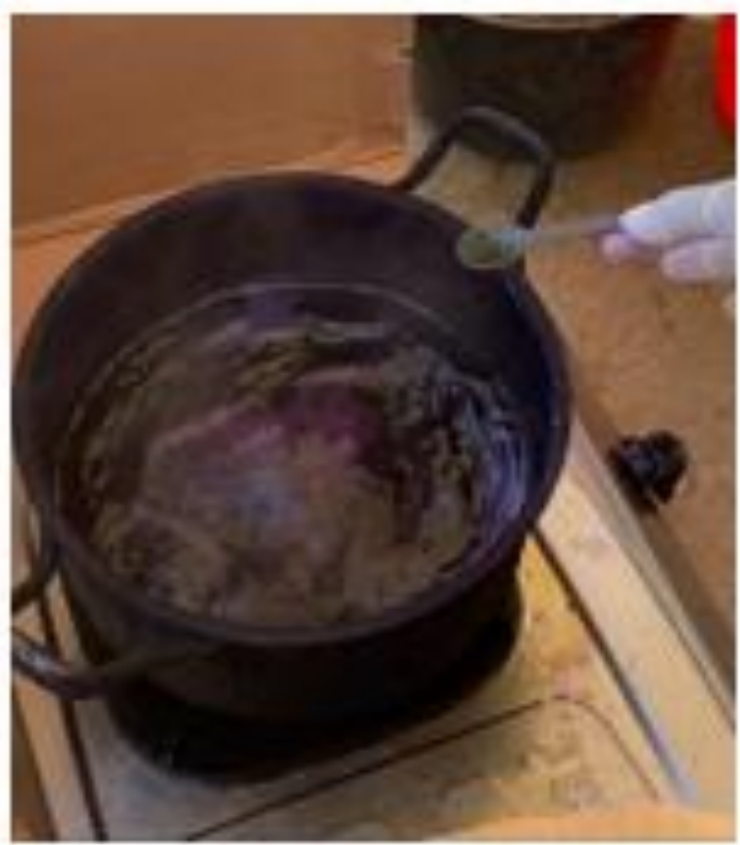

Gambar 1. Proses Pemasukan Zat Warna

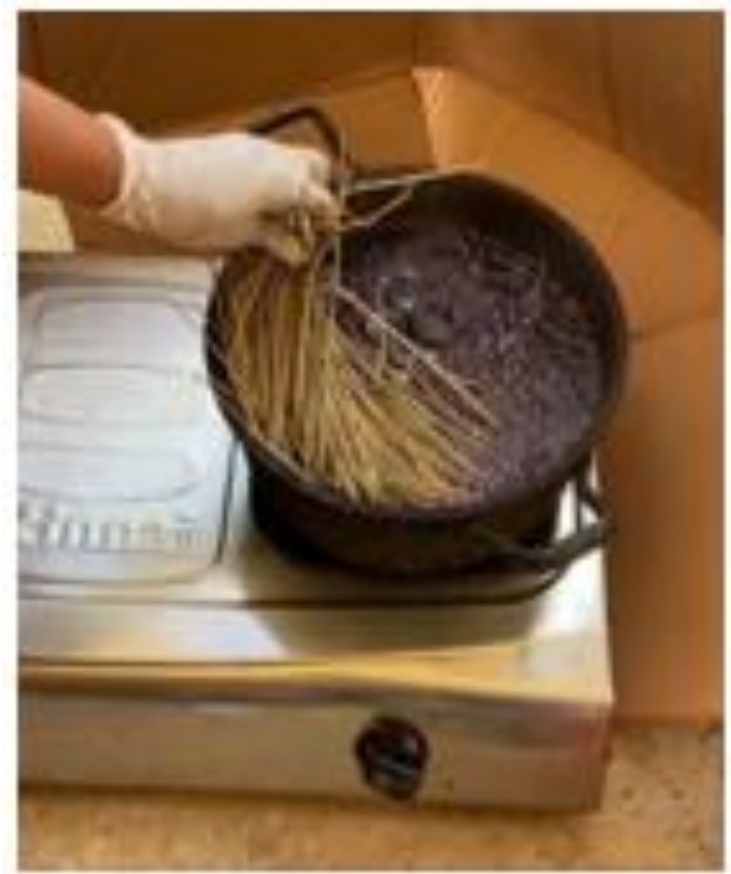

Gambar 2. Proses Memasukan Mansiang atau Daun Wlingi 

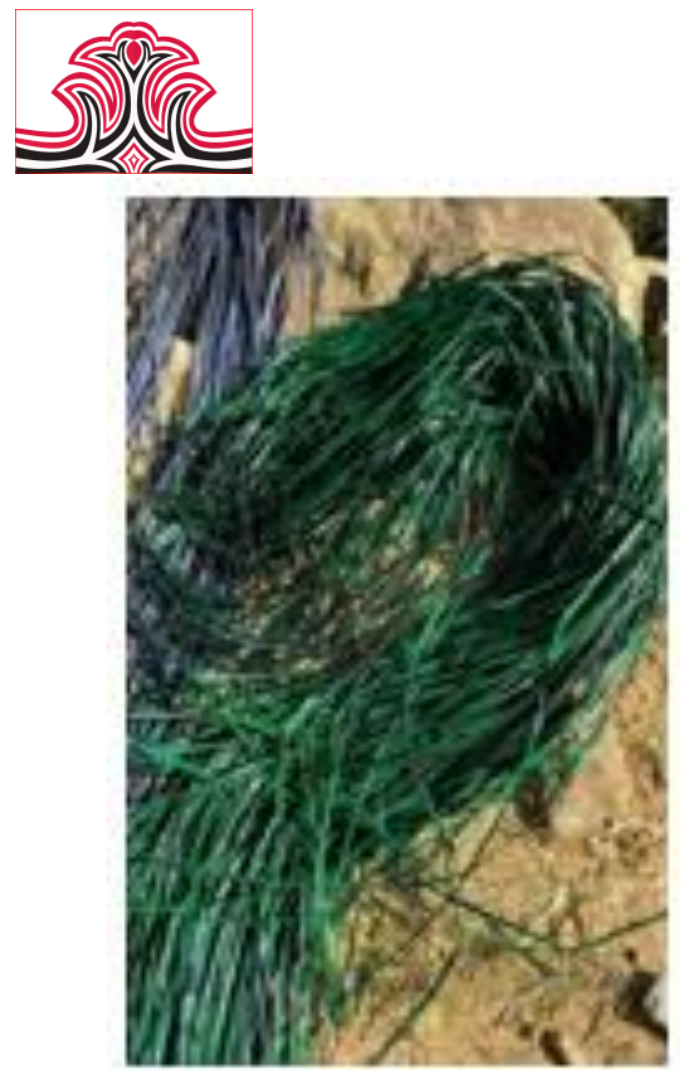

Gambar 3. Mansiang atau Daun Wlingi yang Sudah diwarnai dan Dijemur

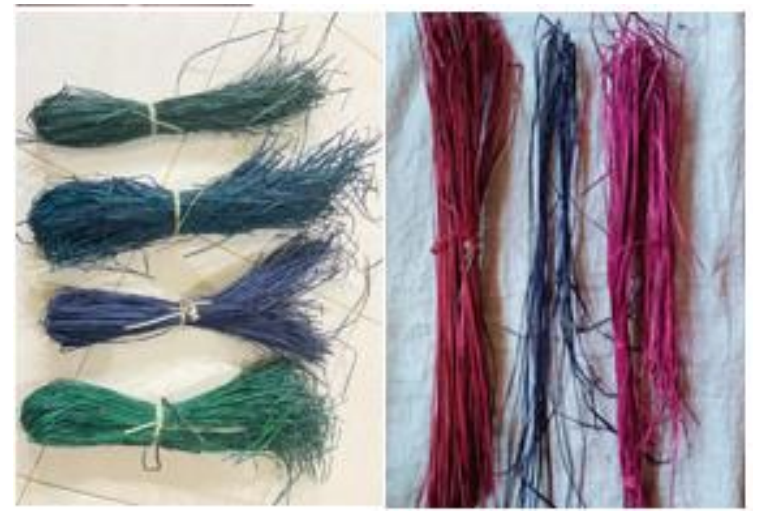

Gambar 4. Daun Wlingi yang Sudah di Celup dengan Zat Warna Basis

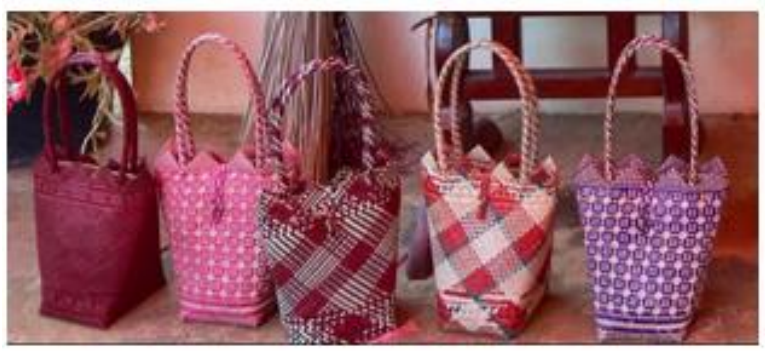

Gambar 5. Hasil Kerajinan Anyaman Mansiang
Gorga : Jurnal Seni Rupa

Volume 10 Nomor 02 Juli-Desember 2021 p-ISSN: 2301-5942 | e-ISSN: 2580-2380

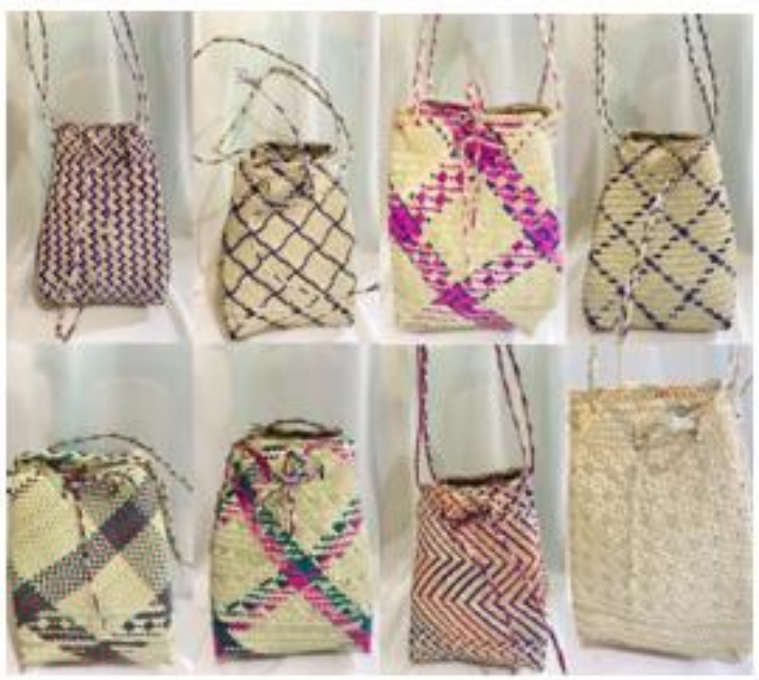

Gambar 6. Beberapa Motif dari Prodak Anyaman di Rumah Anyaman Tabuan Jaya

\section{KESIMPULAN DAN SARAN}

\section{Kesimpulan}

Dari hasil penelitian yang penulis lakukan serta dari analisis data dan pengkajian yang telah diuraikan yakni tentang Pewarnaan Anyaman Mansiang Jorong Taratak di Kubang Kabupaten Lima Puluh Kota (Studi Kasus di Rumah Anyaman Tabuan Jaya) yang ditinjau dari resep dan pewarnaan disimpulkan sebagai berikut: 1). Resep yang digunakan dalam pewarnaan pada kerajinan anyaman mansiang di ruamah anyaman Tabuan Jaya yaitu menggunakan Volt 1:10 untuk pencelupan $200 \mathrm{gr}$ mansiang atau daun wlingi menggunakan air $2000 \mathrm{ml}$ dengan zat warna 0,1 disetiap 200 gr mansiang atau daun wling., 2). Proses Pewarnaan anyaman mansiang di Rumah Anyaman Tabuan Jaya. Pewarnaan yang digunakan yaitu ada 2 pewarna yaitu, dengan menggunakan pewarna sintetis menggunakan zat warna basis dan pewarna cat menggunakan cat biovarnish. Pewarna sintetis menggunakan zat warna basis dikarenakan warna yang dihasilkan baik dan dapat menyerap ke dalam serat mansiang atau wlingi sehingga warnan yang dihasilkan pekat. Proses pewarnaa mulai dari menyediakan alat dan bahan berupa kompor, panci dan bahan berupa mansiang atau daun tumbuhan wlingi, air, zat warna basis, prosesnya panaskan air hingga hangat masukan zat warna, dan tunggu hingga mendidih, setelah mendidih masukan mansiang dan celup selama 5-10 menit, lalu angkat dan jemur hingga kering, dan siap untuk dianyam. Warna yang dihasilkan berupa warna-warna yang cerah seperti, merah, kuning, hijau, biru, jingga, ungu, dan pink namun warna-warna yang gelap bisa dihasilkan dari mencampurkan beberapa warna, seperti untuk biru kehitaman dihasilkan dari percampuran warna jingga, pink dan ungu,, biru hijau dan ungu menghasilkan 


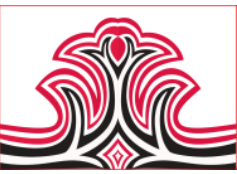

warna abu-abu. Namun pewarna dengan biovarnish dilakukan apabila ada pesanan saja.

\section{Saran}

Berdasarkan hasil penelitian dan kesimpulan yang telah diuraikan adapun penulis mengajukan beberapa saran, saran tersebut anatar lain sebagai berikut: 1). Kepada pengrajin di Ruma Anyaman Tabuan Jaya agar terus mengembangkan warna-warna, baik menggunakan warna sintetis, maupun menciptakan warna-warna baru dengan menggunakan pewarna alami, karena warna merupakan hal mendasar dalm ketertarikan terhadap suatu produk, dan dalam proses pewarnaan hendaknya menggunakan takaran yang lebih akurat seperti timbangan, liter dan juga mengguunakan satu warna satu pwadah atau panci, agar warna yang dihasillkan bisa konsisten,dan juga hendaknya wlingi atau mansiang yang sudah selesai diwarnai dicuci dulu agar mengurangi kelunturan pada prodak-prodak yang dihasilkan agar kedepanya Rumah Anyaman Tabuan Jaya menjadi lebih maju dan berkembang., 2). Kepada Pemerintah Daerah Kabupaten Lima Puluh Kota, untuk dapat ikut serta dalam melestarikan dan terus membimbing sekaligus mengapresiasi karya-karya kerajinan anyaman di Rumah Anyaman Tabuan Jaya, agar bisa terjaga dan terus berkembang untuk generasi selanjutnya., dan 3). Penelitian ini diharapkan dapat memberikan tambahan ilmu pengetahuan sekaligus wawasan pada bidaang pengembangan fashion dan teristimewa dalam pewarnaan kerajinan anyaman mansiang yang bisa dijadikan dalam prodak-prodak fashion.

\section{DAFTAR RUJUKAN}

Bahrudin, A., Widdiyanti, W., \& Wahyono, W. (2020). Pemberdayaan Masyarkat Melalui Pengembangan Desain Produk Anyaman Mansiang di Jorong Taratak Kubang Kecamatan Guguak Kabupaten Lima Puluh Kota. Jurnal Pengabdian Masyarakat.

Herlina, S., \& Palupi, d. y. (2013). Pewarnaan. Jakarta: Kementrian Pendidikan dn Kebudayaan Direktorat Pembinaan Sekolah Menengah Kejuruan.

Kartina, B., Ashar, T., \& Hasan, W. (2012). Karakteristik Pedagang Sanitasi Pengolahan dan Analisis kandungan Rohdamin B Pada Bumbu Cabai Giling di Pasar Tradisional Kecamatan Medan Baru. Medan.

Ningsih, T. (2014). Kerajinan Tekstil Berbahan Mendong Produksi Deriji Craft Du Plembon Sendang Sari Minggir Sleman Yogyakarta. Skripsi: Program Studi Pendidikan Seni Kerajinan Univeristas Negeri Yogyakarta.
Gorga : Jurnal Seni Rupa

Volume 10 Nomor 02 Juli-Desember 2021

p-ISSN: 2301-5942 | e-ISSN: 2580-2380

Noor, F. (2007). Teknologi Tekstile dan Fashion. Yogyakarta: UNY Press.

Patria, M. A. (2015). kerajinan anyaman sebagai peestarian kearifan lokal. dimensi, 1 .

Pratiwi, D. (2012). Raja Soal Semua Mata Pelajaran. Jakarta: JAL Publishing.

Setiati, H. D. (2007). Membatik. Yogyakarta: Pt. Macanan Jaya Cemerlang.

Suarsa, I. W., Suarya, P., \& Kurniawati, I. (2011). Optimasi Jenis Pelarut Dalam Ekstarksi Zat warna Alam dari Batang Pisang Kepok (Musa paradiasiaca L. cv kepok) dan Batang Pisang Susu (Musa paradiasiaca L. cv susu). Jurnal Kimia. 